\title{
A inclusão da subjetividade no ensino da Psicopatologia
}

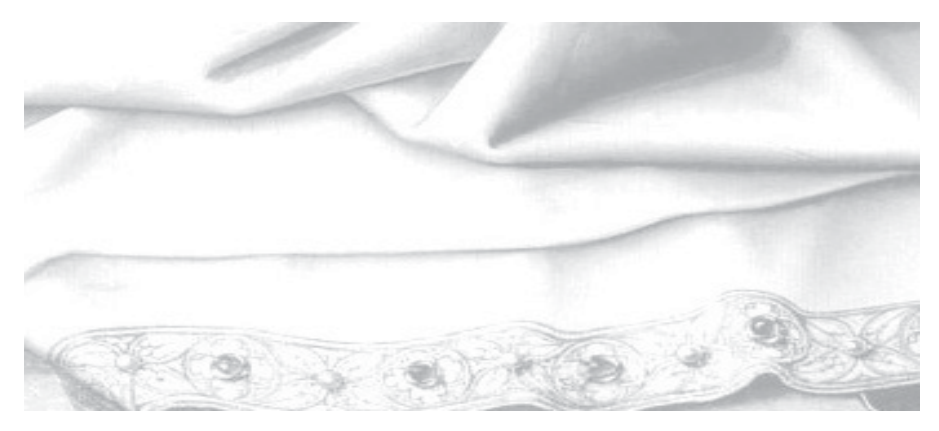

\author{
Octavio Domont de Serpa Junior ${ }^{1}$ \\ Erotildes Maria Leal ${ }^{2}$ \\ Rita de Cássia Ramos Louzada ${ }^{3}$ \\ João Ferreira da Silva Filho4
}

SERPA JUNIOR, O.D. ET AL. Including subjectivity in the teaching of psychopathology. Interface - Comunic., Saúde, Educ., v.11, n.22, p.207-22, mai/ago 2007.

The study of Psychopathology has often been presented in a descriptive form. Though this may be relevant for teaching because it helps students to recognize and identify the symptomatology of each psychopathology, it overlooks the subjective dimension of falling ill and its relational aspects. By approaching the issue from the standpoint of existential anthropology, we present a practical psychopathology teaching experience that regards these dimensions as relevant to the understanding of mental suffering. Two new modes of practical teaching employed in the "Special Psychopathology I" course offered to psychology students of the Federal University of Rio de Janeiro are presented, using the descriptive case study method. The idea is to expand practical teaching, traditionally based on the model of a long clinical interview carried out in the presence of a large group of students that observe everything passively. Our aim is to bring teaching and the practice of psychopathology closer to the ideals of the Brazilian Psychiatric Reform, which views mental illness as a complex phenomenon that involves the relationship of the subject with the world.

KEY WORDS: Psychopathology. Teaching. Subjectivity. Anthropology. Existentialism.

O estudo da Psicopatologia tem sido freqüentemente apresentado em sua dimensão descritiva. Apesar da relevância para o ensino - auxiliar o aluno a reconhecer a dimensão sintomatológica dos quadros psicopatológicos -, exclui a dimensão subjetiva da experiência do adoecimento e seus aspectos relacionais. Partindo da tradição antropológicoexistencial, apresentamos uma experiência de ensino de Psicopatologia que considera tais dimensões relevantes para a compreensão do sofrimento mental. Trabalhando com estudo de caso descritivo, são apresentadas duas novas modalidades de práticas na disciplina Psicopatologia Especial I, oferecida para alunos do curso de Psicologia da UFRJ. A proposta é ampliar o ensino prático, tradicionalmente centrado no modelo da extensa entrevista clínica, realizada diante de um grande grupo de alunos que a tudo assistem passivamente. Pretendemos aproximar o ensino e a prática da Psicopatologia dos ideais da Reforma Psiquiátrica Brasileira, que concebe o adoecimento mental como fenômeno complexo, envolvendo a relação do sujeito com o mundo.

PALAVRAS-CHAVE: Psicopatologia. Ensino. Subjetividade. Antropologia. Existencialismo.

${ }^{1}$ Médico; pós-doutor em Psicopatologia - bolsista CNPq (Centre de Recherche em Épistémologie ASppliquée, Paris); professor, Instituto de Psiquiatria, Universidade do Brasil/Universidade Federal do Rio de Janeiro (IPUB/UFRJ); coordenador, Laboratório de Estudos e Pesquisas em Psicopatologia e Subjetividade (IPUB/UFRJ); coordenador, disciplina Psicopatologia Especial I. Rio de Janeiro, RJ. <domserpa@gmail.com>; <domserpa@ipub.ufrj.br>

${ }_{2}$ Médica; doutora em Psiquiatria e Saúde Mental; professora-visitante, IPUB/UFRJ; pesquisadora, Laboratório de Estudos e Pesquisas em Psicopatologia e Subjetividade (IPUB/UFRJ); docente, disciplina Psicopatologia Especial I. Rio de Janeiro, RJ. <eroleal@uol.com.br> ${ }^{3}$ Psicóloga; doutora em Psiquiatria e Saúde Mental; professora, departamento de Psicologia Social e do

Desenvolvimento, Universidade Federal do Espírito Santo (DPSO/UFES); pesquisadora, Programa Organização do Trabalho e Saúde Mental (IPUB/UFRJ); docente, disciplina Psicopatologia Especial I. Rio de Janeiro, RJ. <ritacrl@uol.com.br>

${ }^{4}$ Médico; doutor em Psiquiatria e Saúde Mental; professor, Faculdade de Medicina, Universidade Federal do Rio de Janeiro; coordenador, disciplina Psicopatologia Especial I. Rio de Janeiro, RJ. <jferreira@ccsdecania.ufrj.br> 


\section{Introdução}

O estudo da Psicopatologia na atualidade tem sido freqüentemente apresentado em sua dimensão descritiva. Fundamento da semiologia psiquiátrica, esse campo de conhecimento foi marcado por diferentes referências teóricas e abordagens em seus pouco mais de duzentos anos de existência. Apesar disso, nas últimas décadas, esta complexidade esteve quase imperceptível a olhares pouco cuidadosos. Embora essa perspectiva tenha a sua relevância para o ensino, na medida em que auxilia o aluno a reconhecer $e$ identificar a dimensão sintomatológica dos quadros psicopatológicos, termina por deixar de fora tanto a dimensão subjetiva da experiência do adoecimento quanto os seus aspectos relacionais e interpessoais.

Com o intuito de ampliar, nessa direção, o ensino de Psicopatologia, iniciamos, na Disciplina Psicopatologia Especial I, oferecida pelo Departamento de Psiquiatria e Medicina Legal da Faculdade de Medicina da UFRJ 5 , para os alunos do curso de Psicologia da UFRJ, duas novas modalidades de atividades práticas. Essa reformulação do ensino prático, tradicionalmente centrado no modelo da entrevista clínica de um paciente, habitualmente internado, realizada por um mestre diante de um grande grupo de alunos que a tudo assistem passiva e, amiúde, desconfortavelmente, visa também colocar o ensino e a prática de Psicopatologia mais próximos dos ideais que norteiam o conjunto de transformações das práticas assistenciais em psiquiatria no Brasil, a chamada Reforma Psiquiátrica. Procuramos, com isso, não deixar os alunos restritos à abordagem psicopatológica centrada na descrição dos elementos do adoecimento mental, mas favorecer o conhecimento do sofrimento psíquico do ponto de vista de quem o experiencia, assim como o caráter relacional e contextual das expressões clínicas dos transtornos mentais. Essas iniciativas têm como expectativa destacar, para os alunos, a complexidade do adoecimento metal $e$ o alcance diferencial das diversas abordagens psicopatológicas.

\section{Pressupostos éticos e conceituais}

Em uma época na qual a Psicopatologia tem se tornado cada vez mais superficial e sem nuances, o desafio do seu ensino, particularmente do seu ensino prático, se impõe a todos aqueles que consideram que seu intento não se resume a oferecer uma descrição objetiva dos sinais e sintomas, desempenhada por uma espécie de "observador" ideal, universal, livre de compromissos teóricos e isento de juízos de valor ${ }^{6}$. Qualificada como Psicopatologia Descritiva (Berrios, 1996, 1993), e freqüentemente confundida, de maneira abusiva e totalmente equivocada, com a Psicopatologia Fenomenológica, sobretudo, na psiquiatria anglo-saxã (Monti E Stanghellini, 1996; Bovet \& Parnas, 1993), essa forma de entender a Psicopatologia embasa as modernas classificações psiquiátricas. Ao se pretender objetiva, ateórica, e ao escamotear a sua incontornável dimensão avaliativa (Fulford et al., 2005; Fulford, 2004, 1994), acaba se limitando por oferecer listas de sintomas tomados em seu valor de face, compondo
${ }^{5}$ O Departamento de Psiquiatria e Medicina Legal é chefiado pela Prof. Alícia Navarro Dias de Souza. 
7 Para uma introdução a esta discussão, ver Serpa Jr., 2003.
${ }^{8}$ Uma notável exceção a este estado de coisas são os dois volumes de Martins (2005, 2003). mosaicos planos e sem gestalt, dos quais qualquer incidência da subjetividade do doente é completamente erradicada. As vivências subjetivas daqueles acometidos por algum tipo de sofrimento moral são imediatamente assimiladas a categorias e esquemas formais que lhes conferem uma inteligibilidade apaziguadora para o observador, confirmando a análise de Foucault (1994) sobre o monólogo da razão sobre a loucura, que se instala a partir da constituição dos saberes "psi". Nesse cenário, como ouvir as vozes da loucura e como torná-las audíveis aos nossos alunos?

Esse modo de operar da Psicopatologia traz embutida, como não poderia deixar de ser, uma concepção de saúde e doença e, antes disso, uma idéia acerca do que deve estar subjacente à partilha entre o normal e o patológico. Só que nada disso é trazido à luz e essas discussões são naturalizadas $e$ neutralizadas. "Naturalizadas" no sentido de um entendimento da natureza como intrinsecamente oposta à cultura e, portanto, não passível de interpretações. O debate do tema "normal e patológico", que deveria ser prévio a qualquer Psicopatologia, é completamente elidido, e a partilha entre as duas condições é compreendida como uma questão de ordem quantitativa, passível de mensuração por diferentes escalas e instrumentos estruturados, tornando-se visível por meio de procedimentos estatísticos ${ }^{7}$. Nessas condições, o campo do patológico obedece a uma inteligibilidade compatível com aquilo que Canguilhem (1982) chamou de Teoria Ontológica da Doença, que toma os diferentes tipos de sofrimento físico e mental exclusivamente em sua objetividade, elementos totalmente externos ao sujeito, quer se entenda este em sua dimensão moral, quer se entenda este apenas como totalidade orgânica. Se tal concepção de doença pode dar a impressão - ilusória - de satisfazer as condições de possibilidade de exercício de uma medicina somática, ela não dá conta das exigências de uma Psicopatologia, já que esta é a subjetividade em sua inteireza.

O desafio do ensino da Psicopatologia em outros moldes torna-se ainda mais agudo diante da pouca disponibilidade de material didático que vá além do previsível. Os modernos manuais de Psicopatologia, cada vez mais, parecem livros de semiologia - na melhor das hipóteses - ainda que sem qualquer problematização ${ }^{8}$ acerca dos procedimentos semiológicos (Serpa Jr. 1996; Silva Filho, 1997). Ou, na pior das hipóteses, assemelham-se a glossários, mais ou menos extensos, meros léxicos dos Manuais de Classificação Diagnóstica. Em geral, são organizados mediante uma apresentação de sintomas referidos a uma psicologia das faculdades mentais de extração oitocentista e, originalmente, descritos com base no exame de pacientes confinados em manicômios à mesma época. No tesouro semiológico apresentado por esses manuais, geralmente, convivem termos oriundos de tradições conceituais díspares, se não antagônicas.

Acreditamos que uma Psicopatologia digna deste nome deve atender ao que formulou Stanghellini (2004, p.9):

...iluminar primariamente a qualidade das experiências subjetivas, seus significados pessoais e o padrão pelo qual elas estão situadas como partes de totalidades significativas (...) principalmente concernida com a corporificação e a intersubjetividade. 
É isto que norteia a nossa proposta, ainda incipiente, de reformulação do ensino prático de Psicopatologia. Não temos a pretensão ingênua de poder encontrar, por esta via, os meios para suspender o aludido monólogo da razão sobre loucura. Buscamos pura e simplesmente resgatar o seu pathos, primeiro, lógica e cronologicamente, e, ainda assim, negligenciado. O pathos, como bem nos lembra Canguilhem (1982), sempre antecede o logos. Uma Psicopatologia que seja só logos, sem pathos, não terá mais utilidade do que uma lâmina sem fio (Monti \& Stanghellini, 1996).

Não queremos dizer com isto que uma abordagem descritiva, objetiva, não tenha o seu lugar no ensino de Psicopatologia. Certamente o tem, sobretudo, quando se trata de propósitos práticos que dependam da formulação de uma hipótese diagnóstica confiável, em um vocabulário comum aos praticantes do campo, possibilitando, assim, a comunicação entre eles. Por esta razão, a necessidade de aprender a realizar uma entrevista diagnóstica de forma competente permanece como um dos elementos centrais do aprendizado em psicopatologia. Mas não o único. Existem outros propósitos práticos em jogo na clínica da saúde mental e no ensino e pesquisa da Psicopatologia. A abordagem descritiva encontra logo os seus limites quando se trata de ter acesso à experiência subjetiva - ao pathos - daqueles que temos sob os nossos cuidados. Queremos ensinar uma Psicopatologia que não descarte a subjetividade, mas, em vez disso, faça desta o seu interesse primeiro. Não no sentido de um enclausuramento solipsista, mas, pelo contrário, revelando a sua relação indissolúvel com a alteridade e o mundo no qual se enraíza. Essa subjetividade, por sua vez, não é tomada como uma substância etérea, não material, mas sim como primordialmente corporificada. Não temos a ambição ingênua e equivocada de pretender fazer da Psicopatologia uma teoria geral da subjetividade. Buscamos apenas proporcionar aos nossos alunos um entendimento acerca do seu pathos, da experiência de sofrimento e dor moral dos nossos pacientes, tomando essa dimensão experiencial em seu caráter eminentemente qualitativo, avaliativo e holístico, no sentido da alteração de uma forma de vida em sua totalidade.

\section{Psicopatologia Descritiva ou Psicopatologia Sintomatológica-Criteriológica}

No campo da Psicopatologia, é possível observar uma tensão entre duas perspectivas de aproximação do fenômeno psicopatológico que deveriam ser complementares, mas que tem sido estabelecida em termos de hegemonia de uma e quase exclusão de outra. Como já adiantamos acima, encontramos na Psicopatologia Descritiva - tendência hegemônica - um adelgaçamento da análise psicopatológica, que se reduz aí a uma sintomatologia, no sentido da descrição objetiva de um repertório de sintomas. Isto descola o estudo da Psicopatologia do plano das vivências (subjetivas) e o remete para a objetividade do quadro nosográfico no qual se expressa o diagnóstico.

Kraus $(2003$; 1994) chama esse tipo de procedimento de Psicopatologia Sintomatológica-Criteriológica e pode ser caracterizada como uma Psicopatologia representacionalista (Parnas \& Bovet, 1995). Dito de outro 
modo, ela entende que as entidades clínicas/categorias diagnósticas com as quais lidamos são como representações mentais de espécies naturais existentes de modo objetivo no mundo externo, previamente a qualquer encontro com uma consciência humana doadora de sentido, independentes, portanto, do observador. Uma categoria diagnóstica, de acordo com esse entendimento, será tão mais verdadeira quanto melhor, ou mais acuradamente, representar o mundo objetivo. Essas representações são expressas na linguagem, tomada como um intermediário epistêmico entre o sujeito que conhece e o mundo das espécies naturais formando, assim, o vocabulário da Psicopatologia. A forma pela qual a linguagem é implicitamente entendida aqui supõe que se relaciona com o mundo de forma literal, unívoca e independente de contexto (Parnas \& Bovet, 1995). Essa abordagem em Psicopatologia caracteriza-se pelo seu operacionalismo (Parnas \& Bovet, 1995; Bovet \& Parnas, 1993), o qual se refere à organização daquele vocabulário em regras operacionais, ou critérios diagnósticos. Estes, por sua vez, visam à ordenação dos sinais e sintomas descritos, segundo princípios lógicos, produzindo, com isto, o aumento da confiabilidade ou fidedignidade do diagnóstico, deixando em segundo plano a sua validade. Tal tipo de procedimento conduz a uma seleção das manifestações clínicas, de modo que aquelas que possuem um caráter mais experiencial, subjetivo - como alterações na consciência de si e da sintonização afetiva com o entorno - tendem a ser descartadas, em detrimento daquelas mais exuberantes, objetivas, comportamentais. Uma consulta aos Manuais de Classificação disponíveis (CID 10 e DSM-IV), bem como à maioria dos manuais de Psicopatologia disponíveis, é suficiente para ilustrar esse tipo de procedimento.

\section{Psicopatologia da primeira e da segunda pessoa}

Em contraposição à Psicopatologia Sintomatológica-Critériológica, Kraus (2003, 1994) descreve o que chama de Psicopatologia AntropológicaFenomenológica, a qual sobrevive em uma condição de relativa marginalidade no cenário atual do estudo e ensino da Psicopatologia. Esta, ao contrário da anterior, não lida com sintomas, mas com fenômenos (Kraus, 2003; 1994; Tatossian, 1979). Enquanto os primeiros são concebidos como remetendo a algum tipo de disfunção médica e, apreendidos objetivamente pelo clínico, esvaziando de importância a dimensão subjetiva do paciente, tomado como simples fornecedor de dados semiológicos, os fenômenos manifestam uma forma experiencial global do paciente, entendida como expressão de um tipo particular de relação consigo mesmo, com a alteridade e com o mundo. Aqui o sujeito da experiência, tomado em sua totalidade, ocupa uma posição central. Os fenômenos, portanto, remetem necessariamente a uma totalidade, a uma estrutura, para ganhar sentido, ao contrário dos sintomas, que podem ser tomados um a um, isolados do conjunto ou apenas em justaposição com outros sintomas. Lidamos aqui, portanto, com modos particulares de ser-no-mundo, como diria Binswanger (1970), com base em Heidegger. A consistência experiencial do pathos, a subjetividade do vivido, são privilegiadas como elementos clínicos 
fundamentais. Em outras palavras, a validade é preferida à fidedignidade. A subjetividade em questão, contudo, é compreendida como necessariamente referida à alteridade - intersubjetividade - e ao mundo - intencionalidade -, o que neutraliza os riscos de qualquer tentação solipsista. Ela é corporificada (embodied), no sentido de emergir da relação de um tipo particular de organismo em interação com o meio - humano e físico - em que vive e, neste sentido, é enraizada no seu mundo, situada em contexto (embedded).

Como indicamos acima, contrapor um modelo ao outro não deve sugerir uma alternativa mutuamente excludente, do tipo ou uma coisa ou outra. Pelo contrário, com isto podemos indicar o que se ganha e o que se perde, em termos clínicos, quando se adota cada modelo. Entretanto, é inegável que o cenário da Psicopatologia nos últimos anos vem demonstrando uma crescente exclusão do modelo que privilegia a subjetividade.

Tomando a dimensão subjetiva como eixo, propomos redescrever os modelos propostos por Kraus $(2003,1994)$ em outros termos. Chamaremos a sua Psicopatologia Sintomatológica-Criteriológica de Psicopatologia da terceira pessoa e a sua Psicopatologia Fenomenológica-Antropológica de Psicopatologia da primeira e da segunda pessoa ${ }^{9}$.

\section{Perspectiva da terceira pessoa}

A Psicopatologia da terceira pessoa adota, como pressuposto epistemológico, a Perspectiva da terceira pessoa (Northoff \& Heinzel, 2003). Nela não encontramos lugar para a experiência, para o vivido, apenas para o comportamento tomado objetivamente. Subjetividade e intersubjetividade estão completamente fora de questão. O que se busca é a certeza factual, renunciando-se a qualquer certeza experiencial, fenomênica. Os fatos trabalhados nessa perspectiva podem ser considerados atemporais $e$ fora de qualquer contexto, na medida em que o decurso do tempo e as contingências da história e da geografia não são considerados como relevantes para o seu esclarecimento. Estes fatos podem ser tomados um a um, destacados de suas condições de surgimento e do conjunto de outros fatos que lhes são simultâneos, produzindo, assim, uma fragmentação, uma atomização do objeto de conhecimento. $O$ tipo de corporeidade que interessa nessa perspectiva é a do corpo objetivo, aquilo que Husserl identificou como Körper.

\section{Perspectivas da primeira e da segunda pessoa}

A Psicopatologia da primeira e da segunda pessoa adota, como pressuposto epistemológico, as Perspectivas da primeira e da segunda pessoa (Northoff \& Heinzel, 2003). A Perspectiva da primeira pessoa diz respeito à experiência pré-reflexiva dos próprios estados mentais e corporais: sentimentos "crus", pura experiência, sem reconhecimento ou reflexão. Estes dois últimos, como veremos, já pertencem à perspectiva da segunda pessoa. Temos aqui a pura subjetividade, sem objetividade nem intersubjetividade. Algo na linha do que foi explorado por Nagel (1997) e ficou consagrado como What is it like to be... Aqui, a certeza fenomênica toma o lugar da certeza factual, cabendo diferenciar a acessibilidade imediata da
9 Para maiores

detalhes, ver Serpa Jr., 2006. 
incorrigibilidade. Ao contrário da perspectiva da terceira pessoa, fragmentadora, lidamos, nesta perspectiva, com a totalidade da experiência. A totalidade a qual remete esta perspectiva é a totalidade do corpo vivido (Leib), experienciado no ciclo ação/percepção da exploração do meio pelo organismo vivo. Esta referência à totalidade do organismo vivo é que assegura a condição de centralização, de ponto de vista, de pólo noético do arco intencional que caracteriza esta perspectiva. Na Perspectiva da segunda pessoa (Northoff \& Heinzel, 2003), nós temos o reconhecimento proposicional da experiência Por isso, ela é necessariamente reflexiva $e$ intersubjetiva. Intersubjetiva não só no sentido de comunicação da experiência para um outro, mas também no sentido de que o julgamento $e$ reconhecimento conceitual da experiência como pertencendo a uma determinada categoria de estados psicológicos só é possível pela inserção do sujeito em uma comunidade lingüística. Não temos mais aqui a transparência $e$ a presença da experiência pura, mas, em vez disso, uma semipresença $e$ a translucidez da mediação reflexiva, uma espécie de intersubjetividade intrasubjetiva. A totalidade ainda predomina sobre a fragmentação, porém aquela pode ser tomada em suas partes pelo trabalho da reflexão. Nesta perspectiva, a corporeidade é apreendida numa zona de mediação entre o corpo vivido (ipseidade) e o corpo objetivo (alteridade). Como salientam Zahavi (2003, 2001) e Northoff \& Heinzel (2003), com base nas concepções de Husserl e Merleau-Ponty, é esta mediação imanente à própria corporeidade que subjaz ao estabelecimento da intercorporeidade e da intersubjetividade.

\section{Sujeito experiencial e sujeito narrativo}

Na subjetividade em questão, na Psicopatologia da primeira e da segunda pessoa, seguindo as indicações de Zahavi (2003), podemos reconhecer dois tipos de sujeito: um sujeito experiencial e um sujeito narrativo. O sujeito experiencial apresenta características que remetem àquelas da perspectiva da primeira pessoa. Ele não está aquém, além ou em oposição à experiência. Em vez disso, é um aspecto ou função do seu modo de doação - firstpersonal givenness - a uma centralidade de perspectiva, corporificada (embodied) e situada em contexto (embedded). Trata-se de uma espécie de sujeito ou self básico, que não é uma precondição transcendental nem um construto narrativo, mas uma realidade experiencial imediata da consciência. Neste sentido, seria até mais adequado se falar em subjetividade da experiência em vez de sujeito da experiência. Esta modalidade subjetiva é pré-reflexiva, não proposicional, não conceitual, não temática. O que contraria certo entendimento comum que considera o

${ }^{10}$ Para maiores detalhes desta discussão, ver Dreyfus, 2002; Gallagher, 2000; Zahavi, 2003, 2002, 1999; Zahavi \& Gallagher, 2005. sujeito ou self como o resultado da reflexão, quando não do domínio cognitivo do conceito de self ou sujeito ${ }^{10}$. O que temos aqui é uma presença primária (Sass, 2003; Sass Ex Parnas, 2003), uma consciência de si préreflexiva ou tácita, uma afecção de si (self-affection) que simplesmente acontece, um sentimento básico do existir como um centro vital da experiência, e que chamamos de ipseidade.

O sujeito narrativo, por outro lado, é necessariamente reflexivo e intersubjetivo, na medida em que depende totalmente da inserção do 
indivíduo em uma comunidade lingüística e na sua adesão a valores, ideais $e$ objetivos referidos a uma dada tradição cultural. Nesta modalidade subjetiva, já podemos falar em identidade, personalidade, pessoa. Ela é construída na e por intermédio da narrativa, por meio de um processo aberto, constantemente sujeito a revisões e mudanças de rumo. Este processo acompanha toda a trajetória de vida do sujeito no decorrer do tempo e procura oferecer um relato que dê conta de suas origens, desenvolvimento e destino. O que somos, nesta perspectiva, depende da estória contada por nós e pelos outros a nosso próprio respeito. Lidamos aqui com a definição que Dennett (1993) dá para a noção de sujeito: centro de gravidade narrativa.

\section{Ensino da Psicopatologia e subjetividade}

Consideramos que apenas uma Psicopatologia que tome como elemento central do seu campo de práticas e de reflexão a dimensão experiencial e as diferentes narrativas que cada sujeito é capaz de produzir, para tentar dar conta do seu sofrimento psíquico, pode ser relevante em um cenário de transformação da assistência em saúde mental, como o que vivemos nos últimos vinte anos ${ }^{11}$. Neste período, temos testemunhado a progressiva substituição do modelo hospitalocêntrico por serviços substitutivos, que, cada vez mais, se constituem no mercado de trabalho em potencial para os estudantes que pretendem se dedicar às práticas clínicas em saúde mental depois de formados. Neste novo modelo, estabelecem-se outras modalidades relacionais entre os membros da equipe de cuidados e entre estes e aqueles que estão sob seus cuidados: pacientes e seus familiares. Com os usuários estabelecem-se regimes de convivência menos verticais, mais atentos à realidade em que vivem e de onde nasce e aonde se expressa o seu sofrimento. Deles se espera maior implicação no tratamento e, com isso, ganhos em sua autonomia. Como continuar, então, empregando, como ferramenta psicopatológica exclusiva, um corpo de conhecimentos objetificante, produzido, sobretudo, em um ambiente asilar e identificado confortavelmente com as práticas alienantes do antigo manicômio?

Com as modalidades de ensino prático de Psicopatologia, que apresentaremos a seguir, pretendemos transmitir não apenas uma concepção de Psicopatologia que tenha como eixo as suas dimensões subjetiva e social, mas também apresentar aos estudantes alguns dos novos dispositivos de cuidados em saúde mental ${ }^{12}$.

\section{Novas práticas no ensino prático de Psicopatologia}

Baseadas no referencial apresentado, as atividades práticas propostas na disciplina tiveram início no primeiro semestre letivo de 2005, tendo sido oferecida, até o momento, para cinco turmas da graduação. Algumas das características aparecem descritas nos próximos itens.

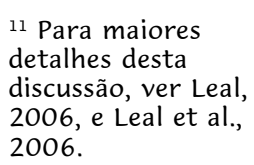

\author{
12 No final de 2006 \\ existiam no Brasil \\ 1011 Centros de \\ Atenção Psicossocial \\ (Brasil, 2007). O \\ crescimento desses \\ serviços tem sido \\ regular e constante: \\ em 2000 eram 208 \\ em todo o país. No \\ estado do Rio de \\ Janeiro existiam 72 \\ Centros de Atenção \\ Psicossocial, sendo 14 \\ no município do Rio \\ de Janeiro ( 11 Centros \\ de Atenção \\ Psicossocial para \\ Adultos, dois para \\ crianças e um para \\ usuários de álcool $e$ \\ outras drogas).
}




\section{Metodologia}

A metodologia empregada foi a do estudo de caso, entendido como a metodologia de pesquisa empírica que investiga um fenômeno dentro do seu contexto de vida real, sendo que os limites entre o fenômeno e o contexto não são claramente definidos. Este tipo de pesquisa lida geralmente com mais variáveis de interesse, baseia-se em várias fontes de evidências e vale-se do desenvolvimento prévio de proposições teóricas para conduzir a coleta e a análise de dados. A unidade (caso) pode ser um indivíduo, mas também pode ser um grupo, uma empresa, instituição, política pública, etc. O caso pode ser único ou múltiplo. O caso decisivo é aquele que serve adequadamente para testar uma teoria bem-formulada (no nosso caso, as formulações

fenomenológicas da perspectiva da primeira e da segunda pessoa). O caso revelador presta-se como possibilidade de observar e analisar um fenômeno geralmente inacessível à investigação científica, no caso, o vivido subjetivo, tão ausente da pesquisa em Psicopatologia nas duas últimas décadas. Estudos de caso podem ser descritivos, exploratórios ou explanatórios, sem qualquer conotação hierárquica vigente nesta distinção. O tipo de generalização que pode advir de um estudo de caso não é, evidentemente, a generalização estatística, decorrente tipicamente de estudos que empregam o método epidemiológico. A generalização que se pode obter valendo-se de um estudo de caso é a que se chama generalização analítica, na qual se emprega uma teoria já desenvolvida como a grade hermenêutica contra a qual são submetidos os resultados do estudo (Yin, 2005).

Resumindo, podemos dizer que a metodologia empregada no presente estudo é a do estudo de caso múltiplo, decisivo e revelador, de caráter exploratório.

A opção pela realização de grupos de usuários como procedimento para a obtenção de narrativas sobre a experiência de sofrimento psíquico se baseia nos desenvolvimentos teóricos de Costa (1989) acerca do efeito facilitador do dispositivo grupal no contexto das práticas terapêuticas em ambulatórios públicos e na exploração pragmática dos grupos, realizada pela equipe de Romme \& Escher $(2000,1997)$ no contexto do trabalho com ouvidores de vozes.

1) O grupo de ensino prático do Hospital-dia do Instituto de Psiquiatria da UFRJ: usuários recebem os alunos.

O convite para participação no grupo é feito pela professora responsável pela atividade, que periodicamente visita a Assembléia Geral do Hospital-dia, e os grupos de acompanhamento do projeto terapêutico dos pacientes, para reiterar convite. É relevante dizer que a professora não faz parte do staff da unidade. Os pacientes são convidados a constituírem um grupo para receber os alunos. A eles é solicitado que digam o que é um Hospital-dia; em que consiste a experiência de ser tratado num dispositivo como esse e a experiência de ser uma pessoa em tratamento psiquiátrico; e o que esperam de um psicólogo em um Hospital-dia. Com essa dinâmica, pretendemos alcançar alguns objetivos:

a) apresentar aos alunos dispositivos de atenção diária $e$ intensiva não centrados na internação; 
b) indicar que o tratamento para pacientes psiquiátricos graves não deve estar centrado na remissão dos sintomas, mas em auxiliá-los a criarem novos modos de viver que, embora diferentes dos momentos anteriores à experiência do adoecimento, possam dar continuidade à própria vida;

c) apresentar aos alunos outras possibilidades de exercício da prática de cuidado, diferente do atendimento individual;

d) ressaltar que a recuperação da capacidade normativa dos pacientes deve ser um dos desafios alcançados com o tratamento, embora isso não signifique o retorno a estado anterior ao adoecimento;

e) indicar aos alunos que o sucesso do tratamento depende, em grande parte, da possibilidade do profissional valorizar o que o paciente toma como importante para si.

Os pacientes que freqüentam a atividade o fazem voluntariamente, $e$, no primeiro período de oferta dessa atividade, alguns pacientes tiveram freqüência regular. As avaliações feitas ao fim de cada semestre com os pacientes indicam que eles atribuem à atividade um caráter terapêutico. $\mathrm{O}$ fato de reconhecerem, na atividade, um espaço onde têm sua palavra valorizada sustenta tal avaliação.

A dinâmica do grupo é livre. No início do grupo, a professora solicita que todos se apresentem (cada grupo de alunos participa dessa atividade duas ou três vezes durante a disciplina ${ }^{13}$ ). Após esse primeiro momento, os pacientes são convidados a descrever o que é o Hospital-dia. Em seguida, considerando as temáticas anteriormente descritas, um diálogo livre se estabelece entre alunos e pacientes. Em geral, os pacientes partem da narrativa de suas histórias de vida. De seus relatos, surgem os temas discutidos ao longo da aula, tais como: o que é viver sentindo-se ameaçado por perseguidores, ser vítima e agente de agressões e discriminação social, as dificuldades de adesão ao tratamento, o que é ser portador de uma doença crônica que dificulta a realização das tarefas mais simples do cotidiano, só para citar alguns. A professora ocupa a função de facilitador desse diálogo. Também participa do grupo um profissional do Hospital-dia que exerce, sobretudo, o papel de observador. Em geral, essa pessoa participa quando alguma interrogação direta lhe é feita. Suas intervenções têm ajudado a reenviar as questões discutidas para os pacientes.

O grupo tem duração de uma hora. Findo este período, os pacientes se retiram e a professora discute com os alunos por trinta minutos. A discussão, livre, costuma abranger principalmente duas questões: como foi a experiência de estar interagindo com pacientes nesse grupo, e em que medida a ferramenta psicopatológica pode ser útil no encontro com pacientes, seus limites e possibilidades. As avaliações feitas pelos alunos, ao fim da disciplina, indicam a capacidade formadora dessa atividade. Não raro referem surpresa ao descobrirem quanto essas pessoas "são fortes" ou como são capazes de construir modos de conviver e entender o seu adoecimento. Em tais narrativas, fica evidente que os alunos conseguiram articular a dimensão sintomatológica dos quadros psicopatológicos à dimensão subjetiva da experiência do adoecimento e seus aspectos relacionais e interpessoais.

Apesar do curto período de realização dessa atividade, algumas
${ }^{13}$ A turma é dividida em seis grupos, formados por até oito alunos cada. 
observações já podem ser feitas. Esse dispositivo mostrou-se potente para indicar a complexidade do campo psicopatológico. Ficou mais fácil, a partir dele, indicar que o modo como percebemos os pacientes decorre, também, das lentes que utilizamos para com eles interagir. A força atribuída às categorias nosológicas, como elementos capazes de informarem sobre o sujeito, foi relativizada. O relato dos pacientes sobre a experiência de ser paciente psiquiátrico foi sempre muito mais rico do que a pura descrição sintomática. As temáticas apresentadas nesses relatos mostraram toda a complexidade do cuidado em saúde mental. Para encerrar a apresentação dessa atividade, serão descritas duas situações que indicaram isso exemplarmente.

Na primeira situação, os pacientes discutiram como, em muitas circunstâncias, é difícil aderir ao tratamento, porque diferente do que usualmente pensamos, os seus sintomas - como delírios e alucinações podem, além de causar problemas para a sua relação com o mundo, também produzir algum tipo de conforto subjetivo. Nesse caso particular, aconteceu um rico debate acerca do que é possível ser feito para ajudá-los a aderir ao tratamento, especialmente quando também um importante elemento de sofrimento e prejuízo está presente.

$\mathrm{Na}$ outra situação, um debate relevante se estabeleceu sobre a revelação do diagnóstico. Foi possível, considerando todas as perspectivas legais e do Direito, discutir o ponto de vista dos pacientes, indicando que essa temática é muito mais do que simplesmente saber o que a lei recomenda, qual é o nosso dever e qual o direito dos pacientes. Foram abordadas questões, tais como: quem revelaria o diagnóstico? Que conseqüências podem ter para o paciente ter o diagnóstico revelado por alguém que considera responsável por seu tratamento e por alguém que não reconhece nesse lugar? Como isso deveria ser dito e discutido? Que fantasias aparecem quando um diagnóstico não é explicitado ou quando é informado sem maiores discussões? Todas essas indagações foram discutidas tomando, como ponto de partida, a opinião dos pacientes. $O$ fato de partirmos da experiência vivida desses pacientes - o que punha em cena as diferentes histórias de vida de relação com a doença $e$ tratamentos que atravessaram - indicou a complexidade envolvida, aspecto pouco perceptível quando elidimos a dimensão da experiência de sofrimento e o reduzimos a um simples elenco de sintomas a serem reconhecidos e enumerados.

2) A segunda atividade proposta na disciplina foi um contato mais estreito com pacientes que freqüentam oficinas terapêuticas no Hospital-dia da instituição. Nesta atividade, ao contrário da anterior, um grupo de alunos encontra-se com um único paciente e este é convidado a falar sobre a sua inserção em uma determinada oficina.

Do mesmo modo como descrito na atividade anterior, a professora não faz parte da equipe do Hospital-dia. Para convidar os pacientes que participam da atividade, ela conta com a colaboração do técnico que coordena a oficina e se incumbe da função de indicar os pacientes para entrevista.

No contato inicial, informa-se ao paciente o tipo de grupo (alunos de 
Psicologia) que irá encontrar e qual o seu objetivo (discutir o lugar da oficina no tratamento). Mediante a concordância do paciente, ele é levado ao encontro do grupo, que se encontra em uma sala de reuniões. O grupo de alunos recebe, então, o paciente, que é chamado a falar, em especial, sobre: qual é a atividade desenvolvida na oficina; o momento em que foi encaminhado para essa atividade; a importância da oficina em seu tratamento; e o relacionamento estabelecido com os colegas e com a coordenadora da atividade. Em meio a essa caracterização, cada paciente vai, a seu modo, inserindo a oficina no contexto do tratamento $e$, aos poucos, falando sobre como adoeceu e sobre como vivencia essa experiência.

Os encontros foram todos muito singulares. O que os interligava era $O$ fato de os pacientes participarem de uma mesma oficina - artes plásticas. A forma como cada um se inseria na oficina variava muito também. Para exemplificar, podemos citar três relatos.

Um dos pacientes, já tendo vivido nas ruas, falava da oficina como algo tão importante que demarcou dois momentos totalmente diferentes em sua vida: antes ele vivia o caos (mental, financeiro etc.); depois da oficina pôde expressar-se melhor e dar alguma direção à sua habilidade para o desenho $e$ a pintura. Com a venda de seus quadros passou a alugar um quarto de hotel onde morava à época da entrevista.

Um segundo paciente, ao contrário, não se interessava muito pela manipulação das tintas ou qualquer outra técnica proposta na oficina. Estava, entretanto, sempre presente, gostava muito do cafezinho que ali era servido e das tarefas de apoio à coordenação que desenvolvia: cuidado com os materiais, monitoramento dos estoques, etc. Dizia que costumava fazer "mandados para a coordenadora", sentia-se muito bem na oficina, considerava que tinha amigos ali. Sua experiência de tratamento estava muito ligada àquela instituição e à oficina, na medida em que antes não recebera qualquer tipo de tratamento. Ficara durante anos apenas "andando pela cidade, ía da Pavuna à Barra, andava, só andava", "estava maluco naquela época", dizia.

Já um terceiro paciente, que também se sentia muito bem na oficina, afirmava sua importância, mas confessava que, sem o chamado insistente da coordenadora, ele nunca teria ido para a atividade. Sua chegada à instituição era sempre acompanhada de um perambular pelo pátio. Só se dirigia à oficina se convocado.

Mediante relatos como esses, debatemos as questões que porventura surjam, em tempo reservado para esse fim, depois da saída do paciente. Retomamos, em geral, a caracterização feita pelo paciente da oficina, suas vivências ali. E ainda: a forma como foi conduzida a entrevista; o que havia chamado a atenção de cada um dos alunos naquele contato etc. Ao final, os alunos são convidados a visitar a oficina, caso se interessem, em dia que pode ser agendado junto à coordenadora da atividade ${ }^{14}$.

\author{
${ }^{14} \mathrm{~A}$ ida, eletiva, à \\ oficina, se passa em \\ um horário \\ alternativo ao da \\ atividade de ensino \\ prático, em função do \\ fato da aula prática \\ iniciar em um horário \\ próximo ao do final \\ das atividades das \\ oficinas. Além disso, \\ apesar do grupo ser \\ relativamente \\ pequeno (até oito \\ alunos), o espaço \\ físico da oficina \\ ficaria apertado se \\ recebesse o grupo \\ todo junto com seus \\ freqüentadores \\ habituais.
}




\section{Considerações finais}

Ratificamos que a supervalorização da observação do fenômeno psicopatológico, sob perspectiva da terceira pessoa, contribui para que os alunos objetifiquem os pacientes e suas experiências. Esse modo de apreender os transtornos mentais não traz prejuízos apenas para o ensino. Longe de poder ser descrito como mero artefato, esse modo de ver produz efeitos também sobre as intervenções que os alunos desenvolverão como profissionais. Esse olhar será instrumento potente para definição de uma clínica onde (1) a idéia de adoecimento mental desconsidera o modo do sujeito operar no mundo; (2) a avaliação psicopatológica se restringe à indicação de presença ou não de sintomas; (3) privilegia como indicador do adoecimento mental apenas a observação da presença/ausência de alterações tipo delírios e alucinações.

Por conta dessa crítica, propusemos as duas atividades descritas que, embora ainda recentes e demandando avaliações atentas às peculiaridades de cada proposta, bem como eventuais ajustes, já revelam, como nos disse um aluno, "algo de mais humano" no contato com o paciente. Dito de outra maneira, a subjetividade resgatada nas aulas práticas, por meio dos relatos em primeira pessoa, traz de forma clara, para o ensino, nossa aposta numa clínica não reducionista, uma clínica que recupere e respeite as singularidades e que deve ser sustentada no interior dos cursos de Psicologia.

\section{Agradecimentos}

Agradecemos a colaboração de todos os pacientes que participaram das atividades propostas na disciplina. Agradecemos, também, à Madalena Pizzaia, Coordenadora do Hospital-dia do IPUB/UFRJ; à Eliane Santos, Coordenadora do "Atelier da Vida"; e à Nuria Malajovich Muñoz, pelas discussões no Laboratório e pela versão do resumo em espanhol.

\section{Colaboradores}

Os autores participaram, igualmente, de todas as etapas de elaboração do artigo.

\section{Referências}

BERRIOS, G.E. The history of mental symptoms: descriptive psychopathology since the nineteenth century. Cambridge: Cambridge University Press, 1996.

BERRIOS, G.E. Phenomenology and Psychopathology: was there ever a relationship? Compr. Psychiatry, v.34, n.4 , p.213-20, 1993. 
BINSWANGER, L. Sur la direction de recherche analytico-existentielle en psychiatrie [1945]. In: Analyse existentielle et psychanalyse freudienne: discours, parcours, et Freud. Paris: Gallimard, 1970. p.51-84.

BOVET, P.; PARNAS, J. Schizophrenic delusions: a phenomenological approach. Schizophr. Bull., v.19, n.3, p.579-97, 1993

BRASIL. Ministério da Saúde. Coordenação Geral de Saúde Mental. Saúde Mental no SUS: acesso ao tratamento e mudança do modelo de atenção. Relatório de gestão 2003-2006. Braília, 2007.

CANGUILHEM, G. O normal e o patológico. Rio de Janeiro: Forense Universitária, 1982.

COSTA, J.F. Psicanálise e contexto cultural: imaginário psicanalítico, grupos e psicoterapias. Rio de Janeiro: Campus, 1989.

DENNETT, D.C. La conscience expliquée. Paris: Odile Jacob, 1993.

DREYFUS, H. L. Intelligence without representation: the Merleau-Ponty's critique of mental representation: the relevance of phenomenology to scientific explanation. Phenomenol. Cogn. Sci., v.1, p.367-83, 2002

FOUCAULT, M. Préface. In: Dits et écrits. Paris: Gallimard, 1994. v.1. p.159-67.

FULFORD, K.W.M. Facts/values: ten principles of value-based medicine. In: RADDEN, J. (Org.). The philosophy of Psychiatry: a companion. Oxford: Oxford University Press, 2004. p.205-34.

Closet logics: hidden conceptual elements in the DSM and ICD classification of mental disorders. In: SADLER, J.Z.; WIGGINS, O.P.; SCHWARTZ, M.A. (Orgs.). Philosophical perspectives on psychiatric diagnostic classification. Baltimore: The Johns Hopkins University Press, 1994. p.211-32.

FULFORD, K.W.M.; BROOME, M.; STANGHELLINI, G.; THORTON, T. Looking with both eyes open: fact and value in psychiatric diagnosis? World Psychiatry, v.4, n.2, p.78-86, 2005.

GALLAGHER, S. Philosophical conceptions of the self: implications for cognitive science. Trends Cogn. Sci., v.4, n.1, p.14-21, 2000.

KRAUS. How can the phenomenological-anthropological approach contribute to diagnosis and classification in psychiatry? In: FULFORD, B.; MORRIS, K.; SADLER, J.; STANGHELLINI, G. (Orgs.). Nature and narrative: an introduction to the new philosophy of psychiatry. Oxford: Oxford University Press, 2003. p.199-216.

Phenomenological and criteriological diagnosis: different or complementary? In: SADLER, J.Z.; WIGGINS, O.P.; SCHWARTZ, M.A. (Orgs.). Philosophical perspectives on psychiatric diagnostic classification. Baltimore: The Johns Hopkins University Press, 1994. p.148-60.

LEAL, E.M. Psicopatologia do senso comum: uma psicopatologia do ser social. In: SILVA FILHO, J.F. (Org.). Psicopatologia hoje. Rio de Janeiro: CCS/UFRJ, 2006. p.102-31.

LEAL, E.M.; SERPA JR., O.D.; MUÑOZ, N. M.; GOLDENSTEIN, N.; DELGADO, P.G. Psicopatologia da autonomia: a importância do conhecimento psicopatológico nos novos dispositivos de assistência psiquiátrica. Rev. Latinoam. Psicopatol. Fund., v.9, n.3, p.433-46, 2006.

MARTINS, F. Psicopathologia I: prolegômenos. Belo Horizonte: PUCMINAS, 2005.

Psicopathologia II: semiologia clínica. Brasília: Universidade de Brasília, 2003.

MONTI, M.R.; STANGHELLINI, G. Psychopathology: an edgeless razor? Compr. Psychiatry, v.37, n.3, p.196-204, 1996.

NAGEL, T. What is it like to a bat? In: BLOCK, N.; FLANAGAN, O.; GÜZELDERE, G. (Orgs.). The nature of consciousness: philosophical debates. Cambridge: MIT Press, 1997. p.519-27. 
NORTHOFF, G.; HEINZEL, A. The self in philosophy, neuroscience and psychiatry: an epistemic approach. In: KIRCHER, T.; DAVID, A.S. (Orgs.). The self in Neuroscience and Psychiatry. Cambridge: Cambridge University Press, 2003. p.40-55.

PARNAS, J.; BOVET, P. Research in psychopathology: epistemological issues. Compr. Psychiatry, v.36, n.3, p.167-81, 1995.

ROMME, M. ; ESCHER, S. (Orgs.). Na companhia das vozes: para uma análise da experiência de ouvir vozes. Lisboa: Estampa, 1997.

ROMME, M.; ESCHER, S. Making sense of voices: a guide for mental health professionals working with voice-hearers. London: Mind Association, 2000.

SASS, L. A. Self-disturbance in schizophrenia: hyperreflexivity and diminished self-affection. In: KIRCHER, T.; DAVID, A.S. (Orgs.). The self in Neuroscience and Psychiatry. Cambridge: Cambridge University Press, 2003. p.242-71.

SASS, L.A.; PARNAS, J. Schizophrenia, consciousness and the self. Schizophr. Bull., v.29, n.3, p.42744,2003

SERPA JR., O.D. Subjetividade, valor e corporeidade: os desafios da psicopatologia. In: SILVA FILHO, J.F. (Org.). Psicopatologia hoje. Rio de Janeiro: CCS/UFRJ, 2006. p.25-101. Indivíduo, organismo e doença: a atualidade de O Normal e o Patológico de Georges

Canguilhem. Psicol. Clín., v.15, n.1, p.121-35, 2003. Para uma semiologia do mental. Cad. IPUB, v.5, p.149-53, 1997.

SILVA FILHO, J.F. A semiologia, seu saber e a psiquiatria. Cad. IPUB, v.5, p.155-63, 1997.

STANGHELLINI, G. Disembodied spirits and deanimated bodies: the psychopathology of common sense. Oxford: Oxford University Press, 2004.

TATOSSIAN, A. Comptes rendus du Congrès de Psychiatrie et de Neurologie de langue française: phénoménologie des psychoses. Paris: Masson, 1979. Tome I.

VERZTMAN, J.S. Será possível transformar a prática do ensino prático? In: FIGUEIREDO, A.C.; SILVA FILHO, J.F. (Orgs.). Ética e saúde mental. Rio de Janeiro: Topbooks, 1996. p.115-22.

YIN, R.K. Estudo de caso: planejamento e métodos. 3.ed. Porto Alegre: Bookman, 2005.

ZAHAVI, D. Michel Henry and the phenomenology of the invisible. Cont. Philosophy Rev., v.32, p.22340, 1999.

Beyond empathy: phenomenological approaches to intersubjectivity. In: THOMPSON, E. (Org.). Between ourselves: second-person issues in the study of consciousness. Thorverton: Imprint Academic, 2001. p.151-67.

Phenomenology of self. In: KIRCHER, T.; DAVID, A.S. (Orgs.). The self in Neuroscience and Psychiatry. Cambridge: Cambridge University Press, 2003. p.56-75.

First-person thoughts and embodied self-awareness: some reflections on the relation between recent analytical philosophy and phenomenology. Phenomenol. Cogn. Sci., v.1, p.7-26, 2002.

ZAHAVI, D.; GALLAGHER, S. Phenomenological approaches to self-consciousness. In: ZALTA, E.N. (Org.). The Stanford Encyclopedia of Philosophy (Spring 2005 Edition). Disponível em: <http:// www. plato.stanford.edu/archives/spr2005/entries/self-consciousness-phenomenological/>. Acesso em: 26 abr. 2005. 


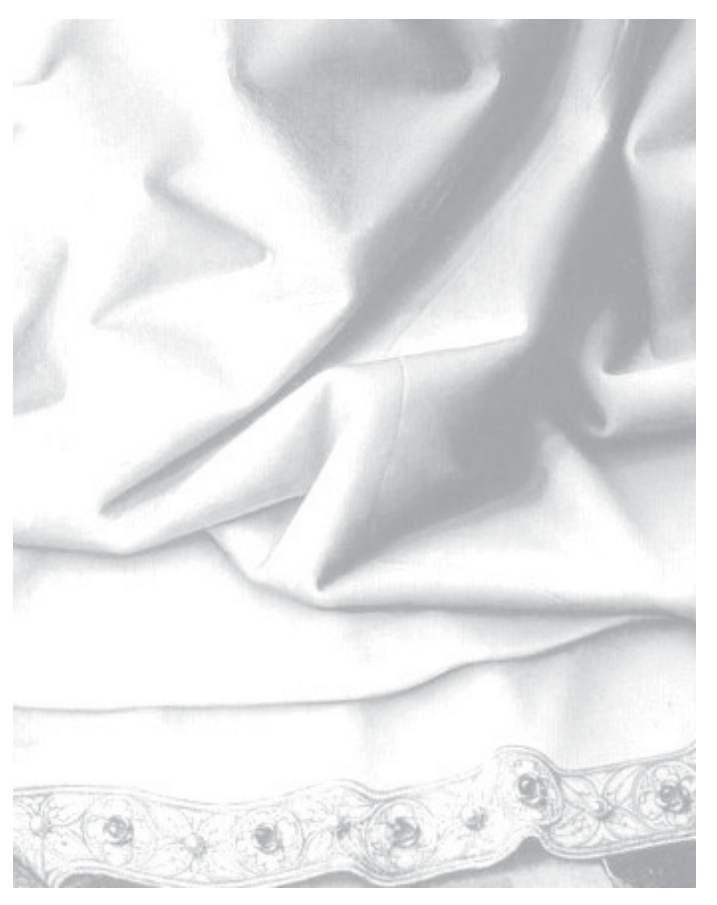

SERPA JUNIOR, O.D. ET AL. La inclusión de la subjetividad en la enseñanza de Psicopatología. Interface - Comunic., Saúde, Educ., v.11, n.22, p.207-22, mai/ago 2007.

El estudio de Psicopatología suele presentarse en su dimensión descriptiva. Esa perspectiva tiene pertinencia para la enseñanza, dado que ayuda el alumno a reconocer la dimensión sintomatológica de los cuadros psicopatológicos. Todavía excluye la dimensión subjetiva de estar enfermo cuanto a sus aspectos relacionales. Partiendo de la antropológica existencial, presentamos una experiencia de enseñanza de Psicopatología que considera tales dimensiones relevantes para la comprensión del sufrimiento mental. Siguiendo el estudio de caso descriptivo, presentamos dos nuevas modalidades de prácticas de Psicopatología Especial I, dictada para alumnos del curso de Psicología de una universidad brasileña. Buscamos modificar la enseñanza práctica, tradicionalmente centrada en el modelo de la gran entrevista clínica realizada delante de un gran grupo de alumnos que asisten a todo de forma pasiva. Pretendemos aproximar la enseñanza y la práctica de Psicopatología a los ideales de la Reforma Psiquiátrica Brasileña que toma la enfermedad mental como fenómeno complejo, considerando la relación del sujeto con el mundo.

PALABRAS CLAVE: Psicopatología. Enseñanza. Subjetividad. Antropología. Existencialismo. 